\title{
Monjes, estudiantes y militares: la crisis de 1974 y el principio del fin del régimen militar socialista de Birmania
}

\author{
Monks, students and military: \\ The 1974 crisis and the beginning of the \\ end for Burma's Socialist Military Regime
}

DANIEL GOMÀ*

Resumen: A menudo reducidos a una breve mención en la investigación sobre la Birmania contemporánea, los hechos de 1974 son un episodio muy importante en su historia reciente y en su desarrollo político posterior. Las protestas contra el gobierno, aplastadas con violencia por el ejército, fueron el primer gran aviso de las dificultades de la "vía birmana al socialismo", experimento revolucionario y utópico de corte militarista desarrollado desde 1962, y el precedente de la revolución de 1988 que pondría fin al régimen militar del general Ne Win.

Palabras clave: Birmania; vía birmana al socialismo; estudiantes; crisis económica; ejército.

Abstract: Often reduced to the footnotes of contemporary research on Burma, the events of 1974 were crucial in the country's recent history and subsequent political development. The anti-government protests were violently crushed by the army but marked the first major evidence of the difficulties facing the 'Burmese Way to Socialism', a revolutionary and utopian military experiment developed since 1962, and the precedent of the 1988 revolution that would end General $\mathrm{Ne}$ Win's military regime.

Recepción: 6 de abril de 2017. / Aceptación: 6 de octubre de 2017.

*Universidad de Cantabria, daniel.goma@unican.es 
Key words: Burma; Burmese Way to Socialism; students; economic crisis; army.

El año 1974 fue determinante en la historia reciente de Birmania (actualmente también denominado Myanmar). ${ }^{1}$ Por un lado, marcó la instauración oficial del primer régimen socialista en el país con la consolidación definitiva de lo que se ha llamado la "vía birmana al socialismo", ideología impulsada por el ejército en el poder desde 1962. Al mismo tiempo, el nuevo Estado socialista fue víctima de la mayor crisis política y social, con el consecuente estallido de protestas ciudadanas a raíz de los malos resultados de la política económica. El asunto adquirió mayores dimensiones con el llamado "incidente de U Thant", que ocasionó un levantamiento popular que acabaría siendo sofocado a sangre y fuego por el ejército. Los hechos de 1974 fueron la primera evidencia clara del fracaso de una ideología tan peculiar como la "vía birmana al socialismo", tal como se demostraría finalmente década y media más tarde.

\section{Los antecedentes: del golpe de Estado a la formación del Estado socialista}

La fundación del Estado socialista fue la culminación de un proceso iniciado 12 años antes. En marzo de 1962, las fuerzas armadas birmanas (conocidas oficialmente como Tatmadaw), al mando de su comandante en jefe, el general Ne Win, dieron un golpe de Estado que puso fin al sistema parlamentario que había regido los destinos de Birmania desde su independencia de Gran Bretaña en 1948. Una vez asegurado el poder y suspendida la Constitución democrática de 1947, el nuevo régimen militar impulsó la creación de una formación política propia, y en julio de 1962 nació el Partido del Programa Socialista de Birmania (PPSB), conocido popularmente como Lanzin, con la fi-

${ }^{1}$ Este artículo tiene su origen en la conferencia titulada "La crisis de 1974: el inicio del declive de la "vía birmana al socialismo", celebrada en el marco del XII Congreso de la Asociación de Historia Contemporánea (Madrid, septiembre de 2014). Aquí se amplía y profundiza en los aspectos tratados en dicha conferencia. 
nalidad de convertirse en el vínculo entre el régimen militar y la sociedad. Su ideología fue conocida como la "vía birmana al socialismo", doctrina revolucionaria y nacionalista que pretendía impulsar una transformación política, económica y social del país y crear una nación próspera y avanzada, donde los uniformados serían los garantes de la modernización del Estado. En realidad, se trataba de una ideología sincrética que mezclaba marxismo y socialismo no marxista, humanismo y tradición budista birmana, todo eso acompañado de un conveniente pragmatismo y envuelto en un espíritu nacionalista. En lo económico, la "vía birmana al socialismo" defendía la nacionalización de la economía, la autarquía y el centralismo económico, lo que garantizaría, supuestamente, la consecución de una nueva sociedad de carácter socialista.

A comienzos de los años setenta, Ne Win y sus camaradas advirtieron de la necesidad de que el PPSB dirigiera el gobierno militar y sustituyera en esta labor al Consejo Revolucionario, institución que había dirigido el régimen desde 1962. Ello implicaba una institucionalización del régimen político y la necesidad de crear un gobierno constitucional, donde el poder estuviera en manos de una autoridad civil. Con este objetivo, en abril de 1972, Ne Win y otros 250 mandos renunciaron al uniforme y volvieron a ser civiles (Wiant, 1981, p. 65). A continuación redactaron una Constitución y celebraron un referéndum para legitimar el futuro gobierno "civil". Dicho plebiscito tuvo lugar entre el 15 y el 31 de diciembre, con una participación ciudadana cercana a $95.5 \%$ del censo. El texto constitucional fue aprobado con 94.5\% de los votos (Fistié, 1985, p. 201). ${ }^{2}$

La nueva Constitución entró en vigor el 3 de enero de 1974. El país cambió oficialmente su nombre al de República Socialista de la Unión de Birmania (RSUB) y se instauró definitivamente el socialismo como ideología de Estado. Asimismo, se institucionalizó el liderazgo político del PPSB en la escena política birmana al asentarse en el artículo 11 de la Constitución que era el único partido político legal y el encargado de liderar

\footnotetext{
${ }^{2}$ Tales cifras nunca fueron verificadas por observadores internacionales y son más que dudosas.
} 
el Estado (Government of the Socialist Republic of the Union of Burma, 1974, p. 4).

La Constitución de 1974 también establecía la elección de un parlamento unicameral de 451 diputados, denominado oficialmente Asamblea del Pueblo y que se renovaría cada cuatro años. Como órgano supremo del Estado, también designaría al Consejo de Ministros (gobierno) y al Consejo de Estado, institución que elegiría al presidente de la RSUB, esto es, el jefe del Estado, y cuyas funciones eran principalmente simbólicas. Las elecciones a la Asamblea del Pueblo (27 de enero-10 de febrero), exclusivamente con candidatos del PPSB, conllevaron el nombramiento como diputados de Ne Win y buena parte de sus compañeros de armas. Ne Win fue designado el primer presidente de la RSUB. En el Consejo de Ministros, otro exmilitar, Sein Win, fue investido como primer ministro del nuevo gobierno "civil” (Silverstein, 1977, pp. 135-137). El 2 de marzo, exactamente 12 años después de haberlo instaurado, $\mathrm{Ne}$ Win disolvió oficialmente el gobierno militar. Birmania entraba, en definitiva, en la etapa socialista.

\section{La crisis económica: los males de la "vía birmana al socialismo"}

Los cambios acontecidos entre 1971 y 1974 no implicaron en la práctica un cambio de poderes. Si bien el PPSB se erigió en el eje sobre el que se asentaba el nuevo régimen político, el verdadero poder siguió siendo el Tatmadaw. El PPSB se transformó simplemente en un partido de la clase militar dotado de una máscara civil. En realidad, la dictadura militar socialista entró en una segunda etapa. La consecuencia real fue que los problemas, en lugar de resolverse, se agravaron, y el objetivo final del régimen -que el nuevo Estado socialista resolviera la situación económica e incrementara el bienestar de la sociedad, asegurando así la estabilidad política y social- no se cumplió.

Las dificultades eran diversas e incluían desde cuestiones de insurgencia y unidad nacional hasta corrupción y mala administración, pero el mayor conflicto era el agravamiento de la situación económica. Al respecto, el objetivo fundamental del 
régimen militar desde su instauración en 1962 había sido evitar que el país dependiera del comercio exterior y, por ello, las funciones de producción y distribución, tanto internas como externas, pasaron al control del Estado, lo que redujo al mínimo la actividad económica privada y, en determinados ámbitos, como la industria, se prohibió incluso en su totalidad (Steinberg, 1981, p. 35). La nacionalización económica emprendida en la década anterior tenía por finalidad asegurar la autosuficiencia, gracias, entre otras cosas, a la creación de empresas e industrias nacionales que disminuyeran lo más posible las importaciones. La industria ligera y la colectivización agrícola fueron los ejes centrales de la reforma económica socialista. El problema fue que las medidas tomadas, pese a algunos éxitos iniciales, tuvieron efectos totalmente contrarios a los esperados, y la gestión de la economía por parte de los altos mandos del ejército, carentes de toda preparación en ese ámbito, no hizo sino agravar la situación. Con la fuga de empresas extranjeras y el caótico control de la economía por parte del Estado surgió un mercado negro de bienes de consumo y hubo un descenso general del nivel de vida (Perry, 2007, p. 27).

El primer gran error fue reformar un sector agrícola que hasta entonces funcionaba y permitía obtener grandes divisas gracias el excedente de producción que se exportaba. La instauración del movimiento de cooperativas vino acompañada de un nuevo sistema de préstamos agrícolas basados en el tipo de cultivos. Con el fin de incrementar la producción de arroz, principal recurso agrícola, se extendieron las tierras de cultivo y se implantó el barbecho como elemento de cultivo con el fin de mejorar la fertilidad de la tierra (Charney, 2009, pp. 121-122). También se decretó un reparto más equitativo de los terrenos. El objetivo era que los campesinos entregaran una cuota de su producción, previamente establecida en función de la cosecha, a cambio de un precio fijo que, a ojos de los campesinos, era muy bajo. De esta manera el arroz, por ejemplo, era subvencionado por el Estado, que se encargaba de suministrarlo a la población. Sin embargo, el sistema de cooperativas no resultó del agrado de los campesinos y la situación, en lugar de mejorar, empeoró.

En la segunda mitad de los años sesenta la situación era cada vez más delicada. A pesar del incremento de la producción, 
la oposición del campesinado a las medidas empezaba a tener consecuencias que afectaban especialmente el comercio exterior, pues las exportaciones de arroz habían disminuido, lo que llevó a Birmania a perder su posición de líder mundial en este campo. El valor de las exportaciones en 1970-1971 era de sólo la mitad del que tenían en 1963 (Cady, 1976, p. 271). No menos importante, la reducción de las exportaciones de arroz, principal fuente de divisas, amenazaba con anular los avances en la industria, cuyo desarrollo se fundamentaba en los beneficios del comercio agrícola. La producción industrial no tardó en estancarse y pronto quedó paralizada ante la escasez de materias primas y piezas de repuesto. Asimismo, la caída de las exportaciones agrícolas y la reducción de las importaciones afectaron también las finanzas públicas, pues en ambos casos los productos eran tasados al salir y al entrar (Fistié, 1985, p. 218). A finales de la década de 1960 era obvio, incluso para el régimen militar, que los objetivos fijados en la "vía birmana al socialismo" habían fracasado.

A comienzos de los años setenta, la economía se encontraba en una situación muy complicada y en el Primer Congreso del PPSB (julio de 1971) se reformuló el programa económico socialista. Las dificultades para consolidarlo llevaron a cambios importantes que empezaron a notarse a partir de 1972. Entre ellos estaba la evidencia de que el triunfo de la "vía birmana al socialismo" no tendría lugar hasta pasados 20 años, y que para ello sería necesario corregir diversos aspectos, como, por ejemplo, permitir cierta actividad económica privada, reducir el costo del nivel de vida, eliminar radicalismos en la política agrícola y mejorar la producción (Government of Burma, 1973, pp. 3-4). El régimen militar birmano se preparaba para hacer frente a un nuevo contexto político en el que debía asegurar, ante todo, su legitimidad como gobernante.

Para recomponer la situación económica, se puso en marcha en 1971 un plan de desarrollo cuatrienal (hasta 1975) con el fin de incrementar la producción, pero los resultados fueron poco esperanzadores desde el comienzo. En septiembre de 1972, $\mathrm{Ne}$ Win alertó de una posible escasez de arroz para finales de año. El anuncio propició un estallido de pánico de la población, que empezó a acumular alimentos, lo que desembocó en una 
creciente especulación y en el alza espectacular del precio de los bienes de consumo, especialmente del arroz y del aceite de cocina. Para frenar esta situación, en enero de 1973, el gobierno lanzó una campaña de hostigamiento contra los llamados “insurgentes económicos", esto es, los especuladores, y fueron detenidos más de 500 distribuidores y traficantes en Rangún y Mandalay (“Food dealers arrested", 1973, p. 6; Tun, 1973, p. 18).

Esta situación llevó al régimen de $\mathrm{Ne}$ Win a dejar de controlar parte de la economía, y, en mayo de 1973, se ordenó la suspensión temporal de la exportación de arroz. Se decretó cierta liberalización económica y se permitió que, tras pagar una cuota en función de la producción, el resto lo pudieran vender los campesinos en el mercado libre. La consecuencia fue que la producción se redujo todavía más, ya que los campesinos acaparaban su producción y entregaban sólo una parte pequeña al gobierno; el resto lo vendían. El arroz y otros alimentos resultaron insuficientes para la distribución a través de las cooperativas estatales; las raciones oficiales y subvencionadas se redujeron. El gobierno era incapaz de alimentar a la población y la respuesta de esta última fue buscar en el mercado negro lo que le faltaba, pero a cambio de una subida diaria de precios de la que se aprovechaban los comerciantes privados y los campesinos. Sólo en Rangún, el índice de precios de consumo subió $54 \%$ entre abril de 1972 y abril de 1974 (Arumugam, 1975, p. 42). El malestar social era evidente.

De todas las distorsiones de la economía, la más grave era, sin duda, el auge considerable del precio del arroz, alimento básico de la población. Según datos del propio gobierno, entre finales de 1972 y finales de 1973, su precio se había doblado en las cooperativas de distribución oficiales (ya de por sí incapaces de suministrar alimentos a toda la población), mientras que en el mercado negro los precios habían subido 130\% (Government of the Socialist Republic of the Union of Burma, 1975, p. 120). Además, el sistema de distribución tenía deficiencias crónicas y estaba dominado por la corrupción. Este problema venía acompañado de otro también muy grave: el de los bajos salarios, pues no habían subido al mismo ritmo que el costo de la vida, lo que implicó que las dificultades económicas para el 
trabajador medio se acentuaran (Arumugam, 1975, pp. 44-45). Con el fin de evitar el estallido social, el gobierno tuvo que decidir, a comienzos de 1974, que las reservas de arroz destinadas a la exportación (principal fuente de divisas) fueran a parar al mercado interno, con el consecuente impacto en las finanzas públicas (Martin, 1975, p. 131). Sin embargo, la medida no fue suficiente y la tensión social no tardó en estallar.

\section{Protestas sociales}

Si exceptuamos la represión del ejército del movimiento estudiantil en julio de 1962, al inicio de la dictadura militar, ${ }^{3}$ el PPSB apenas tuvo problemas en la primera década ante una protesta social escasa. Generalmente, los reclamos empezaban con una queja específica y no tanto contra el régimen en sí, lo que hacía que la protesta fuera fácilmente solucionada por el Estado. Si exceptuamos los movimientos armados que se resistían desde hacía décadas al gobierno de Rangún (comunistas, grupos vinculados a minorías étnicas, etc.), en lo social el principal grupo opositor eran los universitarios, concretamente los de la Universidad de Rangún y, en menor medida, los de Mandalay. Los estudiantes habían encarado el dominio colonial en los años treinta, y de ese grupo surgirían las figuras más importantes del proceso descolonizador y de la Birmania independiente (Aung San, U Nu, Ne Win, U Thant, etc.), pero después de 1948 habían tenido un papel limitado y, salvo en los incidentes posteriores al golpe de Estado militar, su activismo había sido silenciado gracias a la vigilancia de los servicios secretos de $\mathrm{Ne}$ Win. No obstante, a partir de finales de los años sesenta el movimiento estudiantil empezó a ser cada vez más activo, aunque no fue sino hasta un lustro más tarde cuando demostró su fuerza al régimen.

Aparte de su tradicional lucha en favor de la democracia, los estudiantes se habían convertido en un segmento de descontento social latente debido a las escasas posibilidades que

${ }^{3}$ El golpe de Estado de 1962 fue contestado por los estudiantes de la Universidad de Rangún; el ejército penetró en el campus y abrió fuego sobre los manifestantes. Se estima que hubo un centenar de muertos. 
tenían de encontrar empleo después de graduarse. El régimen de $\mathrm{Ne}$ Win había fomentado desde 1962 la enseñanza de las disciplinas científicas y técnicas con el fin de impulsar sus objetivos de desarrollo socialista. La consecuencia, sin embargo, fue una abundancia exagerada de ingenieros en detrimento de otras carreras, y de los 5000 estudiantes que salían de las universidades anualmente, la mitad no encontraba trabajo. A comienzos de los años setenta había más de 20000 licenciados desempleados (Fistié, 1975, p. 275). Si a ello añadimos que la situación económica era cada vez más delicada y que la corrupción del sistema conllevaba que la obtención de un trabajo fuera, ante todo, por vinculación al régimen, el malestar estudiantil era evidente (estudiante de la Universidad de Rangún, comunicación personal, 30 de diciembre de 2009).

El otro grupo de oposición lo encabezaba el sangha, la orden monástica budista. El activismo político de los pongyis (monjes budistas) se remontaba a siglos atrás, cuando se opusieron a reyes y caudillos, y habían sido importantes durante los periodos colonial y posindependiente. Los monjes no participaban, en teoría, en la política (carecían del derecho de voto según establecía la Constitución), pero tenían gran influencia social y no dudaban en implicarse políticamente, como se demostró en el caso de $\mathrm{U} \mathrm{Nu}$, que ganó las elecciones de 1960 gracias al apoyo del sangha. El régimen militar socialista había intentado, de manera poco exitosa, controlar a los monjes, y se ganó su antipatía cuando quiso hacer un registro de sus miembros a mediados de los años sesenta (Mendelson, 1975, pp. 341-345). Sin embargo, ambos grupos, estudiantes y monjes, curiosamente no desempeñaron un papel destacado en el estallido de las protestas y sólo más tarde tuvieron un verdadero protagonismo en la crisis del régimen militar socialista.

De hecho, el movimiento de oposición a la dictadura de $\mathrm{Ne}$ Win se desencadenó de manera casi espontánea durante el periodo inmediatamente posterior a las elecciones de enerofebrero de 1974 y a la instauración del nuevo régimen constitucional dominado por el PPSB. Las causas de esta agitación social fueron el deterioro general de la economía y la mala gestión del gobierno (Fistié, 1985, p. 273). La corrupción gubernamental no hizo sino empeorar el escenario y los precios 
cada vez más elevados en el mercado negro sembraron una creciente alteración social, añadida al enojo de la población por la prosperidad de algunos altos mandos militares que no dudaron en aprovecharse de la situación para controlar este mercado ilegal (Smith, 1999, p. 269). En un discurso dirigido a sus correligionarios del PPSB a mediados de mayo, el propio Ne Win reconoció que "el problema más urgente al que nos enfrentamos es el alza de precios” (“General Ne Win's speech on price increasing”, 1974, p. 2).

No está claro dónde empezaron las protestas, aunque es seguro que fue en la zona central del país. Al parecer, la primera protesta tuvo lugar entre los trabajadores del sector ferroviario en Myintge, al sur de la segunda ciudad del país y núcleo económico vital de la región central, Mandalay. A comienzos de mayo, decidieron ir a la huelga en demanda de un incremento de las raciones de arroz, y acusaron al gobierno de dar preferencia en su distribución a los obreros del sector armamentístico y de incumplir así la idea de que en un Estado socialista todos los trabajadores eran iguales ante la ley (Seekins, 2002, p. 94).

Las protestas no tardaron en extenderse a otras instalaciones públicas de las ciudades vecinas. En Chauk, al sudoeste de Mandalay, donde se encontraban las instalaciones petrolíferas más importantes del país, el trabajo quedó paralizado. Los obreros de Chauk ya tenían una tradición reivindicativa desde los años treinta, cuando se habían enfrentado al gobierno colonial británico en la lucha por la independencia. A mediados de mayo, los trabajadores de la zona se declararon en huelga en reclamo de un aumento salarial y el suministro de arroz a un precio razonable. Otras protestas siguieron en otros centros petrolíferos (como la vecina Yenangyaung) y en la ciudad de Meiktila, punto vital de comunicaciones entre norte y sur y entre este y oeste de Birmania. Aunque a comienzos de junio el gobierno había logrado poner fin a las protestas en el sector petrolero al aceptar las demandas de los huelguistas, hubo consecuencias. El descontento se extendió a Rangún de la mano del sector ferroviario, muy influyente y poderoso en un país donde el tren era el medio de transporte por excelencia. En realidad, la inconformidad se amplió a todo el sector público de 
transportes y a las factorías de la región de Rangún, incluida el área portuaria de la capital, principal puerta de entrada y salida del comercio marítimo. A comienzos de junio, más de una cuarentena de factorías, entre ellas las más importantes del país, estaban en huelga (Peiris, 1974, p. 29).

La primera reacción de las autoridades fue detener a varias decenas de huelguistas en Rangún, pero en un contexto de creciente inflación, precios desorbitados y un malestar social extendido, al que se añadió la demanda de mejoras laborales, la respuesta del gobierno no hizo sino incendiar más la situación. Las huelgas se propagaron con acciones cada vez más contundentes de los huelguistas, apoyados ahora por los movimientos estudiantiles. Se llegó a retener a funcionarios y oficiales del gobierno, la violencia se incrementó y se destruyeron equipamientos. En los primeros estallidos, las huelgas habían consistido en simples paros de la producción dentro de las fábricas y sin muestras de hostilidad antigubernamental, pero con el paso de las semanas, los incidentes tomaron un cariz cada vez más político y surgieron reclamos de un regreso al sistema anterior a 1962 (Seekins, 2002, p. 94).

Las protestas amenazaban con ampliarse y la paralización de las comunicaciones y del transporte de mercancías hacía que la población fuera cada vez más consciente de la situación. Además, era evidente que los trabajadores se organizaban mejor en sus protestas, y el apoyo de los universitarios, tradicional movimiento de oposición, no hizo sino despertar mayores temores en el gobierno. Confrontado con una creciente desaprobación del orden establecido y ante una amenaza a su autoridad, desconocida en 12 años de gobierno militar, Ne Win decidió atajar el descontento y ordenó la intervención del ejército. El 6 de junio, unidades del Tatmadaw y de la policía abrieron fuego en una fábrica textil de Thamaing, cerca de Rangún, y en el astillero de Sinmaleik, en la propia capital. Según fuentes militares, la intervención armada se debió a que las protestas desembocaron en alborotos de la mano de agitadores externos. Oficialmente murió una veintena de personas, entre trabajadores y civiles, y resultaron heridas 73, incluidos 13 policías (Cady, 1976, p. 277). Sin embargo, otras informaciones señalan que la cifra total de muertos estaría entre 100 y 300, y 
que la responsabilidad principal de la acción recayó en unidades chins y kachins (etnias minoritarias del país) traídas especialmente del frente de batalla contra la insurgencia armada (Smith, 1999, p. 269; Tun, 1974a, p. 8). La fuerte represión puso un fin abrupto a las huelgas. Por otro lado, consciente de la necesidad de evitar el enfrentamiento con trabajadores y funcionarios, desde el gobierno se relajaron los controles en el suministro de arroz a los empleados públicos. Aunque las protestas finalizaron, los problemas en la producción continuaron ante la falta de decisión del gobierno para hacer frente a las dificultades de mantenimiento de unas empresas poco funcionales, poco productivas y poco modernas.

\section{La explosión social: el "incidente U Thant"}

A partir del otoño, la represión desplegada por el régimen de $\mathrm{Ne}$ Win en los meses anteriores parecía haber controlado el malestar social causado por la crisis económica. La calma había regresado a las fábricas, y los centros universitarios, que habían sido cerrados temporalmente para prevenir manifestaciones de apoyo a los trabajadores en huelga, fueron reabiertos (Steinberg, 1981, p. 73). Sin embargo, dicho malestar no tardaría en estallar con toda su virulencia a finales de año. Las lluvias monzónicas de finales de primavera y verano trajeron inundaciones imprevistas en el delta del Irrawaddy, al sur de Rangún y principal zona productora del país, y resultaron destruidas unas 320000 hectáreas de arrozales listos para la cosecha (Tun, 1974b, p. 36). La reducción de la producción llevó a la escasez y el consecuente aumento de precios. El propio Ne Win no dudó en alertar de la complicación al recordar los incidentes de mayo y junio y señalar que "la peor parte del problema laboral es un problema de estómago... [la escasez de] arroz es la raíz de este problema" ("Ne Win's address on rice issue", 1974, p. 2). No menos importante fue la revelación, por una parte de la prensa, de almacenes gubernamentales con reservas de comida, medicinas y ropa. La hostilidad social hacia el régimen se incrementó por su ineficiencia al afrontar los problemas (Cady, 1976, p. 277). A finales de año, la RSUB hacía agua y su imagen 
pública estaba por los suelos (estudiante de la Universidad de Rangún, comunicación personal, 30 de diciembre de 2009).

El motivo del estallido social de finales de 1974 fue, sin embargo, un hecho imprevisto y en principio no relacionado con la política nacional ni con el modelo económico socialista. El acontecimiento que vino a agitar de nuevo la escena política y social y a poner contra las cuerdas al régimen de $\mathrm{Ne}$ Win fue el fallecimiento de U Thant, político y diplomático birmano, y la consecuente falta de respeto demostrada por las autoridades hacia su figura.

El 25 de noviembre murió en Nueva York el ex secretario general de Naciones Unidas, U Thant, víctima de cáncer. ${ }^{4}$ Opositor al régimen colonial británico en su juventud, había tenido un cargo político muy importante en el periodo democrático en la cartera de ministro de Información (1948-1953) y de secretario personal del primer ministro $\mathrm{U} \mathrm{Nu}$ (1953-1957). En 1957 fue nombrado embajador de Birmania en la Organización de las Naciones Unidas en Nueva York, donde se forjó un gran prestigio. Así, tras la muerte de Dag Hammarskjöld en un accidente aéreo en septiembre de 1961, fue designado nuevo secretario general de las Naciones Unidas, puesto que ocupó hasta diciembre de 1971. Durante su mandato tuvo un papel relevante en la resolución de la crisis de los misiles de Cuba y no dudó en criticar a Estados Unidos por su intervención en Vietnam (Seekins, 2006, p. 448). Era la figura birmana más prestigiosa (si no la única) en la escena internacional, y su influencia entre la población birmana sólo era superada por la devoción hacia Aung San, el "padre de la independencia" (estudiante de la Universidad de Rangún, comunicación personal, 30 de diciembre de 2009).

U Thant se había mostrado siempre como un demócrata convencido y, desde el comienzo, mantuvo una oposición frontal a la dictadura instaurada por Ne Win en 1962. Como cercano colaborador de $\mathrm{U} \mathrm{Nu}$, denunció la encarcelación de dirigentes democráticos y apoyó al ex primer ministro en su lucha por la democracia. Nu fue liberado en 1966 e incluso se le

${ }^{4} U$ es un término de respeto para dirigirse a un varón adulto y se añade precediendo al nombre. 
permitió viajar. En 1969, aprovechando uno de estos viajes, no dudó en exiliarse y ponerse al frente de un movimiento de oposición con base en Tailandia. En su aventura, Nu contó con el apoyo de U Thant, quien le permitió leer un discurso en la sede de la Asociación de Corresponsales de Prensa de Naciones Unidas, es decir, en el recinto de la ONU en Nueva York, donde denunció públicamente la dictadura militar birmana. Si Ne Win no apreciaba el prestigio internacional de U Thant, el apoyo de este último a $\mathrm{Nu}$ acabó de enemistarlos definitivamente. Prueba de ello fue que, en su último viaje personal a Birmania en 1971, su presencia fue intencionalmente ignorada por las autoridades, pese a su relevancia internacional (Selth, 1989, p. 10). Algunos informes señalan, asimismo, que tras dejar el cargo en Naciones Unidas, a U Thant y su familia se les negó la entrada a Birmania (Mya, 1992, p. 8).

Sea como fuere, el régimen birmano aceptó el último deseo de U Thant de ser enterrado en su país. La comitiva fúnebre formada por sus familiares llegó a Rangún el 1 de diciembre. Sin embargo, la reacción de las autoridades locales fue extremadamente fría. Ningún representante del régimen acudió al aeropuerto a recibir el cuerpo del ilustre dignatario. $\mathrm{Ne}$ Win cobraba así venganza a su enemigo político. Incluso, un viceministro de Educación, Aung Tin, fue destituido fulminantemente por sugerir en una reunión gubernamental que escuelas y universidades del país permanecieran cerradas el día del funeral como señal de respeto al difunto (Seekins, 2002, p. 95). Además, se decidió que U Thant fuera enterrado en el capitalino cementerio público de Kyandaw sin honores de Estado, el día 5.

Las autoridades locales no tardaron en darse cuenta del error de no haber previsto la reacción popular. En el recorrido fúnebre desde el aeropuerto se fue concentrando cada vez más gente en un silencio reverente hacia la celebridad fallecida. El ataúd fue expuesto durante varios días en un pabellón erigido expresamente para ello en el hipódromo de Kyaikkasan, no muy lejos del recinto de la Universidad de Rangún. Allí, para desagrado del régimen, durante cuatro días se formaron largas colas de miles de ciudadanos que fueron a rendir homenaje y a demostrar así su estima al líder internacional (Selth, 1989, p. 10). Se calcula que el día 5 había unas 50000 personas en 
Kyaikkasan para presenciar la ceremonia funeraria ("U Thant's Funeral Arrangements Disrupted”, 1974, p. 1).

La tensión no tardó en explotar. En realidad, el regreso del cuerpo del ex secretario general de Naciones Unidas a Rangún y el nulo respeto de Ne Win a la figura de U Thant sirvieron de catalizador para la liberación de las frustraciones por los problemas sociales y económicos que enfrentaban los birmanos. Muchos desaprobaban la actitud del gobierno, que no envió representante alguno a recibir el cuerpo, y rechazaban que no se le concediera a $U$ Thant un entierro digno de su estatus. Los más críticos eran los estudiantes de la Universidad de Rangún y del Instituto Tecnológico de la capital, cuyas protestas fueron en aumento. Asimismo, había también numerosos pongyis (monjes budistas) que velaban el cuerpo de U Thant (estudiante de la Universidad de Rangún, comunicación personal, 29 de diciembre de 2009).

La situación fue un tanto confusa en los días siguientes. Los incidentes empezaron en vísperas de la inhumación. En la tarde del día 5, unos 10000 estudiantes, con apoyo de los monjes, se apoderaron del ataúd y desfilaron durante varias horas por la ciudad con el ataúd a cuestas, hasta llegar al recinto de la Universidad, donde fue depositado en el Convocation Hall durante tres días. Al parecer, con acuerdo de la familia, el cuerpo fue llevado al campus de la Universidad de Rangún a la espera de una demanda de los estudiantes de que el gobierno encontrara un lugar adecuado para su entierro (estudiante de la Universidad, comunicación personal, 30 de diciembre de 2009). Sin embargo, otras fuentes señalan que los estudiantes, por iniciativa propia, se llevaron el ataúd con los restos de U Thant (Fistié, 1985, p. 275).

El gran apoyo popular a la figura de U Thant y la fuerza de las manifestaciones sorprendieron al gobierno, que hasta entonces había intentado minimizar el problema del enterramiento. Además, los dirigentes observaban con preocupación cómo el control de los acontecimientos había pasado a manos de los estudiantes, que - no menos importante- contaban con el creciente apoyo del sangha. Miles de monjes de todo el país se trasladaban a Rangún para homenajear al difunto, reconocido como gran defensor de la fe. Conscientes del error y visto el apoyo 
popular a U Thant, las autoridades cedieron, y el día 7 ofrecieron un nuevo lugar de enterramiento, concretamente en Cantonment Park, al pie de la pagoda Shwedagon, el lugar más sagrado del budismo birmano, donde se construyó un mausoleo. Asimismo, el difunto sería enterrado con todos los honores y no se tomarían medidas en contra de aquellos que participaran en la procesión funeraria desde el campus al nuevo destino, que tendría lugar a mediodía del día 8 ("U Thant's Burial at Cantonment Park", 1974, p. 1).

La reacción de los estudiantes, sin embargo, fue la contraria a la esperada. Tal vez el gran apoyo popular les hizo creerse más fuertes de lo que eran en realidad y quisieron demostrarlo tomando sus propias decisiones. Según un testimonio de la época, los estudiantes rechazaron la oferta del gobierno por desconfiar de su verdadera intención y percibir que no había garantías de que los estudiantes que habían participado en las manifestaciones no serían detenidos después (estudiante de la Universidad de Rangún, comunicación personal, 30 de diciembre de 2009). ${ }^{5}$ Lo que sí es seguro es que la situación se radicalizó cuando los estudiantes decidieron construir su propio mausoleo en honor a $U$ Thant en el recinto de la universidad, en el antiguo emplazamiento de la Unión de Estudiantes, edificio símbolo de la resistencia estudiantil al golpe de 1962, aplastada violentamente por las autoridades (Selth, 1989, p. 14). Otro testimonio confirma que alumnos más radicales tomaron el control del movimiento estudiantil y que la construcción del mausoleo en el mismo lugar donde se alzaba la antigua sede de la asociación de estudiantes (edificio derribado en 1962) era una provocación en toda regla hacia el régimen de $\mathrm{Ne}$ Win debido a la simbología que rodeaba esta acción (profesor de la Universidad de Rangún, comunicación personal, 5 de enero de 2010).

Una vez construido el mausoleo, en la mañana del día 8, el ataúd, cubierto con una bandera de Naciones Unidas, fue transportado a su lugar de enterramiento, y la familia de U Thant fue invitada a despedirse de su pariente. La acción de los estu-

${ }^{5}$ En realidad, las autoridades habían prometido no tomar medidas contra los que se habían apoderado del ataúd, lo que evidencia cierta confusión entre los estudiantes, probablemente debido a su desorganización interna y a la ausencia de un liderazgo claro entre ellos. 
diantes, apoyados por los monjes, era un desafío a la autoridad de Ne Win y, durante dos días, la universidad de Rangún fue un ir y venir de gente llegada de todo el país para mostrar sus respetos al ex secretario general de la ONU (Selth, 1989, pp. 1516). No sólo eso, durante esos dos días se sucedieron discursos y debates cada vez más críticos al sistema político, la situación social y la corrupción, y se habló de la necesidad de cambio y democracia. Se lanzaron eslóganes contra el régimen militar, calificado de "fascista", y contra el propio Ne Win, cuya vida un tanto disoluta y su afición por las mujeres eran por todos conocidas, pero hasta entonces había sido un tema tabú (estudiante de la Universidad de Rangún, comunicación personal, 29 de diciembre de 2009). En realidad, las demandas de los manifestantes se convirtieron en una sucesión de quejas por agravios sociales, malas condiciones de vida y ausencia de libertades; de este modo, las protestas amenazaron con desbordarse.

\section{La violenta respuesta del régimen y el aplastamiento de las protestas}

La actitud de los estudiantes se convirtió en un desafío abierto al recién instaurado régimen de la RSUB. Cuando advirtieron que los manifestantes no podrían ser persuadidos de ceder en sus acciones y ante la necesidad de mantener la situación bajo control, las autoridades respondieron con firmeza: cerraron el campus universitario y concentraron unidades militares y policiales en Rangún con miras a un asalto al recinto estudiantil. La prensa oficial no dudó en informar de la situación de tensión y en avisar que se recurriría al uso de la fuerza si era necesario para acabar con el "secuestro" del ataúd de U Thant ("Sensibilities of society spurned", 1974, p. 1; "Kyaikkasan and Shwedagon", 1974, p. 2). Los militares no estaban dispuestos a que los estudiantes se reorganizaran como movimiento de oposición.

También estaba la sensible cuestión del papel desempeñado por la familia de U Thant. Antes de su entierro en el mausoleo universitario había sido invitada por los estudiantes a despedirse del fallecido. La prensa oficial, sin embargo, apuntó que la 
familia había intentado evitar esta situación y que hizo un llamado a las autoridades para que se recuperara el ataúd con el fin de evitar "cualquier daño o destrucción [del cuerpo]", e incluso se publicó una carta de los parientes de U Thant en este sentido ("Family appeals for government action to safeguard U Thant's remains", 1974, p. 2). Con ese objetivo, y para evitar el flujo de personas hacia Rangún, se decretaron restricciones de viaje y se ordenó el cierre de todas las instituciones educativas del país (Selth, 1989, pp. 13-14).

En la tarde y la noche del día 10, los alrededores del campus universitario fueron cercados por unidades militares, lo que indicaba que el asalto era inminente. En las primeras horas del día 11, el ejército, apoyado por la policía, entró en el recinto aprovechando que los estudiantes y los monjes allí presentes dormían. En poco tiempo habían sometido las protestas. Los testimonios son poco precisos y divergen en cuanto a la violencia empleada por los militares. Algunas fuentes señalan que no hubo disparos, pero que la violencia empleada fue extrema y se usaron gases lacrimógenos y palos. Sin embargo, la mayoría de los testimonios coinciden en que hubo muertos y que los vehículos blindados no dudaron en pasar por encima de grupos de manifestantes (estudiante de la Universidad de Rangún, comunicación personal, 30 de diciembre de 2009) y que los estudiantes que custodiaban el mausoleo fueron asesinados mediante bayonetas (Mya, 1992, p. 9; Seekins, 2002, pp. 96-97). Cerca de 3000 personas fueron detenidas en el asalto, entre ellas centenares de monjes que fueron apaleados y desprovistos de sus ropajes (Selth, 1989, p. 19). Otro aspecto que destaca es que, al parecer, entre las tropas que asaltaron el campus figuraban unidades de batallones chins traídos del frente de guerra contra las guerrillas comunistas y curtidos en el arte del combate (estudiante de la Universidad de Rangún, comunicación personal, 30 de diciembre de 2009).

$\mathrm{Al}$ alba, el recinto universitario estaba bajo poder gubernamental y miles de manifestantes habían sido detenidos. Se recuperó el ataúd con los restos mortales de U Thant y, fuertemente custodiado, lo llevaron a Cantonment Park, donde poco después de las seis de la mañana fue enterrado en el lugar acordado. $\mathrm{Al}$ acto asistieron únicamente los familiares del difunto 
y representantes de organismos oficiales. La tumba fue sellada con cemento para evitar posibles exhumaciones y el acceso al lugar permaneció temporalmente cerrado ("Proclamation of military administration in Rangoon division", 1974, p. 2).

Si las autoridades pensaron que habían acabado con el problema, estaban muy equivocadas. Las noticias de la brutal irrupción en el campus universitario pronto se extendieron por la capital y sembraron una oleada de descontento social que derivó en disturbios. Aparte de la violencia empleada, los informes de que algunos monjes budistas habían muerto y otros habían sido maltratados, ambos casos considerados actos sacrílegos dentro del budismo, no hicieron sino encender todavía más la ira de la población y, al parecer, hicieron estallar definitivamente los alborotos (profesor de la Universidad de Rangún, comunicación personal, 5 de enero de 2010). En un ambiente de levantamiento popular, miles de estudiantes, monjes y jóvenes, apoyados y jaleados por gente de todas las clases sociales, se enfrentaron a militares y policías en las calles de Rangún en la misma mañana del 11 de diciembre. Los objetivos de los manifestantes eran edificios del gobierno, del PPSB y todo aquello vinculado al régimen, como las comisarías de policía, pero también vehículos y medios de transporte (autobuses, coches, etc.), que fueron pasto de las llamas. Incluso las salas de cine, que eran propiedad estatal, fueron atacadas (estudiante de la Universidad de Rangún, comunicación personal, 29 de diciembre de 2009).

Enfrentado a una rebelión popular desconocida hasta la fecha y en un ambiente de descontrol absoluto, el régimen de $\mathrm{Ne}$ Win anunció el establecimiento del estado de emergencia a partir de las cuatro de la tarde y decretó la ley marcial en toda la División de Rangún. Así, la capital y la región quedaron bajo administración de la Comandancia de Rangún y se ordenó el despliegue de tropas por toda la capital. Se impuso el toque de queda de seis de la tarde a seis de la mañana y se advirtió que a toda persona no militar que anduviera en la calle entre esas horas le dispararían al instante. Por otro lado, se establecieron tribunales de excepción para juzgar los casos de desobediencia a la autoridad. Asimismo, se ordenó el cierre de la red de transporte público, mercados, escuelas, oficinas de gobierno y 
el aeropuerto capitalino de Mingaladon y se prohibió toda manifestación o reunión de cinco o más personas ("Proclamation of military administration in Rangoon division”, 1974, p. 1).

Rangún fue ocupada por unidades del Tatmadaw con el apoyo de la policía y se procedió a poner fin a las protestas. Las tropas no dudaron en disparar a los manifestantes, monjes incluidos, y se detuvo a centenares de personas. Aunque el orden se restableció ese mismo día, al siguiente se repitieron los disturbios y la represión continuó durante dos jornadas más. La calma se restauró a partir del día 15, pero se mantuvo la presencia militar en las calles durante las semanas siguientes $y$, de hecho, la ley marcial no fue levantada en la capital hasta septiembre de 1976 (Charney, 2009, p. 138). Según un informe interno del gobierno birmano, en los incidentes de diciembre fueron arrestadas 2887 personas, de las que se liberó a un millar, y fueron dañados o destruidos 38 oficinas gubernamentales, media docena de comisarías de policía, una decena de cines, unos 70 vehículos entre coches, autobuses y motos, un tren y unos 15 puestos de control de tráfico (Burma, 1977, p. 122).

El número exacto de muertos durante estas protestas que pusieron en jaque al gobierno no se conoce. El gobierno birmano estableció la cifra entre 15 y 20, y en un centenar el número de heridos. Otras fuentes señalan que por lo menos fueron 50 los muertos, y otras incluso destacan que fueron más de un millar; algunas teorías sugirieron que los cuerpos fueron enterrados en fosas comunes al norte de Rangún (Mya, 1992, p. 9; Seekins, 2002, p. 97; Steinberg, 1981, p. 73). Las organizaciones estudiantiles hablaron en su momento de un centenar de muertos en las manifestaciones y los disturbios. Un caso similar es el de los detenidos, pues se señala que pudieron haber sido entre 5000 y 7000 , incluido medio millar de monjes, aunque la mayoría fueron liberados en las semanas siguientes. El resto, unas 65 personas en total, fueron condenadas a diversas penas de cárcel, las más graves de tres a cinco años de reclusión (Smith, 1999, p. 269; Silverstein, 1977, p. 143; Selth, 1989, pp. 22-23; Fistié, 1985, p. 276). 


\section{Conclusión}

El año de 1974 estaba destinado a ser el del triunfo de $\mathrm{Ne}$ Win y su ideología de la "vía birmana al socialismo". Después de años de edificación de su propia versión socialista, los militares birmanos creían haber logrado la legitimidad que el golpe de 1962 les negó y pensaban haber consolidado el PPSB como factor de cohesión social. Pese a su "entronización" como ideología de Estado, la "vía birmana al socialismo" dio signos de agotamiento en 1974, y la mejor prueba fue la crisis económica latente que degeneró en las protestas de las clases trabajadoras, aquellas sobre las que, en principio, pretendía apoyarse el PPSB. No menos importante fue la ilusión de un retorno del gobierno constitucional, que pronto se esfumó, ya que el nuevo gobierno "civil" no tardó en ser percibido por la población como continuación de la dictadura militar de 1962-1974. A pesar de los intentos de los dirigentes nacionales de presentar el sistema político de la República Socialista de la Unión de Birmania como constitucional y elegido por la población, la relación entre sociedad y poder jamás fue estrecha, y este último nunca contó con el apoyo de grupo social alguno, con excepción de las fuerzas armadas. La reacción violenta del gobierno ante las diferentes muestras de oposición fue la demostración más clara y puso de manifiesto que la fuerza era el único medio que conocía el régimen para conservar el poder.

Los hechos de 1974 fueron la mayor demostración de oposición al régimen militar desde el golpe de Estado de 1962, y la primera gran advertencia de las dificultades de la "vía birmana al socialismo" para consolidarse como ideología nacional y resolver los problemas de la sociedad. La dimensión de las protestas confirmó el fracaso de las campañas de movilización impulsadas hasta entonces por el régimen y la ausencia de un vínculo social con el nuevo sistema político. Por primera vez, $\mathrm{Ne}$ Win y sus partidarios del PPSB y del Tatmadaw vieron peligrar su autoridad y temieron perder el poder, como lo prueba el hecho de que fuera la primera vez que se declaraba la ley marcial desde la independencia del país en 1948.

De los diferentes acontecimientos de 1974, el más dañino para el régimen de $\mathrm{Ne}$ Win fue el “incidente U Thant". Si a pri- 
mera vista la reacción popular fue consecuencia de la poca sensibilidad de las autoridades hacia una figura altamente respetada, en realidad se trató de un acto de hostilidad mucho más profundo. Así, las circunstancias que rodearon el traslado del cuerpo del ex secretario general de la onU fueron el catalizador para el estallido de las frustraciones ante los problemas que los birmanos padecían derivados de las desastrosas políticas económicas de la "vía birmana al socialismo" y del autoritarismo del sistema de partido único.

La ineptitud del gobierno para detener la inflación rampante y el alza del precio de los bienes de consumo (especialmente del arroz), así como su incapacidad para promover trabajos adecuados para una creciente población joven, provocaron el deterioro de la situación y el descontento social. En este sentido, las violentas protestas de diciembre "no es que fueran pro-U Thant, sino que eran anti-Ne Win” (profesor de la Universidad de Rangún, comunicación personal, 5 de enero de 2010). La insensibilidad del régimen ante las demandas de los manifestantes por las difíciles condiciones de vida derivó en demostraciones que acabaron por escapar a su control y lo obligaron a recurrir a la fuerza de las armas.

Los hechos de 1974 prepararon el camino a la revolución de 1988 que puso fin al régimen militar socialista. ${ }^{6}$ Por un lado, supusieron las primeras muestras de descontento de las clases trabajadoras hacia las políticas de $\mathrm{Ne}$ Win, pero, sobre todo, marcaron el despertar del activismo político de un movimiento estudiantil que estalló con toda su fuerza una década y media más tarde. Para muchos estudiantes de la Universidad de Rangún y de otros centros de educación superior, los acontecimientos de 1974 fueron su primera experiencia de oposición a la dictadura imperante, como fue el caso, por ejemplo, de Tun Aung Kyaw, presidente del Frente Democrático de Estudiantes de Birmania, uno de los grupos principales que participaron en la revolución de 1988 (Smith, 1999, p. 278). Prueba de ello

${ }^{6}$ La revolución de 1988 no puso fin a la dictadura militar, pero sí al régimen de Ne Win y al sistema político de la RSUB. El poder siguió en manos del Tatmadaw aunque con nuevos dirigentes (muchos de ellos antiguos compañeros de Ne Win), se abandonó la "vía birmana al socialismo" y se optó, a partir de entonces, por el modelo de desarrollo capitalista. 
es que, en junio de 1975, poco después la reapertura de las universidades, hubo nuevas protestas estudiantiles y huelgas de trabajadores que fueron suprimidas por el gobierno, aunque sin la contundencia del año anterior. Casos similares se produjeron en los años siguientes (Charney, 2009, pp. 138; Fistié, 1985, pp. 277-278; Seekins, 2002, pp. 97-98). Por otro lado, y no menos importante, 1974 significó la consolidación de una segunda fuerza de oposición al régimen militar: el sangha, la orden monástica budista. Los monjes, que veían cómo se reducían las donaciones y cómo sus familias sufrían los estragos de la mala situación económica, no dudaron en unirse por primera vez a los obreros, y en especial a los estudiantes, en sus demandas. La represión ejercida contra ellos por el poder marcó un antes y un después en su relación con la dictadura militar. Los monjes también desempeñaron un papel destacado en la revolución de finales de los años ochenta.

Sin embargo, a pesar de la explosión social contra el régimen de Ne Win, éste logró sofocar las protestas y seguir en el poder. La razón principal fue el respaldo absoluto de las fuerzas armadas al sistema político. El Tatmadaw demostró carecer de fisuras y no dudó en aplastar sin contemplaciones las muestras de oposición. Otro factor importante fue una total ausencia de apoyo a los estudiantes y los monjes por parte de los grupos tradicionales de oposición política al régimen, en principio los partidarios del antiguo primer ministro $\mathrm{U} \mathrm{Nu}$. Tampoco mostraron su respaldo las facciones armadas en lucha contra el gobierno de Rangún (comunistas, minorías étnicas, etc.). Eso enlaza con otro aspecto: la nula relevancia internacional de los hechos de 1974. El aislamiento de Birmania impulsado por los militares desde 1962 había alejado al país de la órbita de interés de las grandes potencias en una región -el sudeste asiático-donde, en la misma época, era más importante lo que sucedía en Vietnam y en Camboya, con el inminente triunfo comunista en dichos países.

Los hechos de 1974, y en especial el "incidente U Thant", también revelaron una realidad más preocupante: la ausencia de una alternativa política viable a la dictadura de $\mathrm{Ne}$ Win y el PPSB. Pese a la magnitud de las protestas, no hubo una estructura de oposición organizada y, en general, se desarrollaron en 
condiciones de anarquía, favorecidas por el hecho de que toda acción y decisión se tomaba de manera asamblearia y por aclamación posterior (estudiante de la Universidad de Rangún, comunicación personal, 30 de diciembre de 2009). No surgieron líderes estudiantiles de relevancia, lo que colaboró a las disensiones en el seno del movimiento estudiantil, y tampoco se buscó formar un gobierno alternativo. Incluso el sangha, que tenía más poder para articular socialmente un movimiento de oposición, fue incapaz de ejercer el liderazgo en el seno de una sociedad que lo demandaba.

A pesar de que los hechos de 1974 no lograron derribar el régimen militar, fueron el antecedente de la revolución que 14 años más tarde, en 1988, llevó a la caída del modelo socialista birmano. Así, 1974, el año destinado a ser el principio de la edad socialista de Birmania, se convirtió en realidad en el año del principio del fin de la "vía birmana al socialismo" y, por ende, del régimen del general $\mathrm{Ne}$ Win, que no sobrevivieron a la siguiente década y media.

Dirección institucional del autor:

Facultad de Educación

Universidad de Cantabria

Edificio Interfacultativo

Avenida de los Castros, $s / n$

39005 Santander, España

\section{Referencias}

Arumugam, R. S. (1975). Burma: A political and economic background. Southeast Asian Affairs, 41-48.

Burma (1977). Asia Yearbook 1976 (pp. 121-127). Hong Kong: Far Eastern Economic Review.

CAdy, J. F. (1976). The United States and Burma. Cambridge, MA: Harvard University Press.

Charney, M. W. (2009). A history of modern Burma. Cambridge, MA: Cambridge University Press.

Family appeals for government action to safeguard U Thant's remains. (13 de diciembre de 1974). The Working People's Daily, p. 2.

FIsTIÉ, P. (1985). La Birmanie ou la quête de l'unité: Le problème de la 
cohésion nationale dans la Birmanie contemporaine et sa perspective historique. París: Publications de l'École Française d'ExtrêmeOrient.

Food dealers arrested (1 de febrero de 1973). Forward, p. 6.

General Ne Win's speech on price increasing. (3 de mayo de 1974). The Guardian, p. 2.

Government of Burma. (1973). Long-term and short-term policies of the Burma Socialist Programme Party. Rangún: Ministry of Planning and Finance.

Government of the Socialist Republic of the Union of Burma (1974). The Constitution of the Socialist Republic of the Union of Burma. Rangún: Ministry of Information. Recuperado de http://www. burmalibrary.org/docs07/1974Constitution.pdf

Government of the Socialist Republic of the Union of Burma (1975). Report to the Pyithu Hluttaw on the financial, economic and social conditions of the Socialist Republic of the Union of Burma. Rangún: Ministry of Planning and Finance.

Kyaikkasan and Shwedagon. (10 de diciembre de 1974). The Guardian, p. 2.

MarTin, E. W. (febrero de 1975). The Socialist Republic of the Union of Burma: How much change? Asian Survey, 15(2), 129-135. https://dx.doi.org/10.2307/2643323

Mendelson, E. M. (1975). Sangha and the State in Burma: A study of monastic sectarianism and leadership. Ithaca, NY: Cornell University Press.

Mya, M. (1992). Totalitarianism in Burma: Prospects for economic development. Nueva York: Paragon House.

$\mathrm{Ne}$ Win's address on rice issue. (12 de julio de 1974). Working People's Daily, p. 2.

PEIRIS, D. (13 de septiembre de 1974). Socialism without commitment. Far Eastern Economic Review, 27-30.

Perry, P. J. (2007). Myanmar (Burma) since 1962: The failure of development. Aldershot: Ashgate.

Proclamation of military administration in Rangoon division, military administration orders. (12 de diciembre de 1974). The Guardian, p. 1.

SEeKINS, D. M. (2002). Disorder in order: The army and the State in Burma since 1962. Bangkok: White Lotus.

SeEkins, D. M. (2006). Historical dictionary of Burma (Myanmar). Lanham, MD: The Scarecrow Press.

Selth, A. (1989). Death of a hero: The U Thant disturbances in Burma, December 1974. Brisbane: Griffith University. 
Sensibilities of society spurned (10 de diciembre de 1974). The Working People's Daily, p. 1.

Silverstein, J. (1977). Burma: Military rule and the politics of stagnation. Ithaca, NY: Cornell University Press.

Sмiтн, M. (1999). Burma: Insurgency and the politics of ethnicity. Londres: Zed Books.

STEINBERG, D. I. (1981). Burma's road toward development: Growth and ideology under military rule. Boulder: Westview Press.

Tun, M. C. (4 de enero de 1973). Out of the frying pan. Far Eastern Economic Revierw, 18-19.

Tun, M. C. (11 de julio de 1974a). Increasing tension in Burma. Far Eastern Economic Review, 8-10.

Tun, M. C. (4 de octubre de 1974b). A Race against time for Burma's farmers. Far Eastern Economic Review, 36-37.

U Thant's Burial at Cantonment Park (8 de diciembre de 1974). The Working People's Daily, p. 1.

U Thant's Funeral Arrangements Disrupted (6 de diciembre de 1974). The Working People's Daily, p. 1.

Wiant, J. A. (1981). Tradition in the service of revolution: The political symbolism of Taw-Hlan-Ye-Khit. En F. K. Lehman (Ed.), Military rule in Burma since 1962: A kaleidoscope of viewes (pp. 59-72). Singapur: Maruzen Asia. 